\title{
Maximizing Output Power of a Solar Panel via Combination of Sun Tracking and Maximum Power Point Tracking by Fuzzy Controllers
}

\author{
Mohsen Taherbaneh, ${ }^{1,2}$ A. H. Rezaie, ${ }^{2}$ H. Ghafoorifard, ${ }^{2}$ K. Rahimi, ${ }^{1}$ and M. B. Menhaj ${ }^{2}$ \\ ${ }^{1}$ Electrical and Computer Department, Iranian Research Organization for Science and Technology, Tehran 15815/3538, Iran \\ ${ }^{2}$ Electrical Engineering Department, Amirkabir University of Technology, Tehran 15916-34311, Iran \\ Correspondence should be addressed to Mohsen Taherbaneh, taherbaneh@aut.ac.ir
}

Received 6 September 2010; Revised 2 December 2010; Accepted 27 December 2010

Academic Editor: Raghu N. Bhattacharya

Copyright () 2010 Mohsen Taherbaneh et al. This is an open access article distributed under the Creative Commons Attribution License, which permits unrestricted use, distribution, and reproduction in any medium, provided the original work is properly cited.

\begin{abstract}
In applications with low-energy conversion efficiency, maximizing the output power improves the efficiency. The maximum output power of a solar panel depends on the environmental conditions and load profile. In this paper, a method based on simultaneous use of two fuzzy controllers is developed in order to maximize the generated output power of a solar panel in a photovoltaic system: fuzzy-based sun tracking and maximum power point tracking. The sun tracking is performed by changing the solar panel orientation in horizontal and vertical directions by two DC motors properly designed. A DC-DC converter is employed to track the solar panel maximum power point. In addition, the proposed system has the capability of the extraction of solar panel $I-V$ curves. Experimental results present that the proposed fuzzy techniques result in increasing of power delivery from the solar panel, causing a reduction in size, weight, and cost of solar panels in photovoltaic systems.
\end{abstract}

\section{Introduction}

Nowadays, photovoltaic systems are rapidly expanding and have an increasing role in power-generation technology. Despite the fact that solar panels have high fabrication cost and low efficiency of energy conversion, they are power sources in photovoltaic systems. The reason is that they provide more secure power sources and pollutionfree electric supplies. They generally have nonlinear $I-V$ curves with solar irradiance and temperature dependency. Their maximum power point changes nonlinearly with environmental conditions (solar irradiance, temperature, and degradation level) and load profile. Since the photovoltaic electricity is expensive compared to the electricity from conventional sources, use of all reachable solar panels output power is of interest. Therefore, photovoltaic systems should be designed to operate at their maximum output power in any environmental conditions.

Figures 1(a) and 1(b) show the effect of environmental conditions in a solar panel $I-V$ curves. It can be seen that the $I-V$ curves depend on solar irradiance and temperature.
It should be mentioned that the solar panels' $I-V$ curves are nonlinear, and there is a point on each curve, at which the solar panel can deliver maximum power to its load. This guides us to design a controller to locate the system at maximum power points. Two methods are generally used to increase solar panels output power in photovoltaic systems. In the first one, the system will increase the incident solar irradiance on the solar panel. In that case, the environmental conditions define the quality of the generated power for each load. The system requires a sun tracker to track the sun position for increasing the received solar irradiance by the panels. This method is used for medium- to high-scale photovoltaic systems and has a high cost $[1,2]$. In the other one, solar panels are fixed and load profile defines the quality of the delivered power. Since the system tracks the maximum power point of the solar panels, a maximum power point tracker is used. This method is utilized in smallscale photovoltaic applications $[1,2]$. Combination of these two approaches can raise the reached energy of a solar panel in photovoltaic systems. 


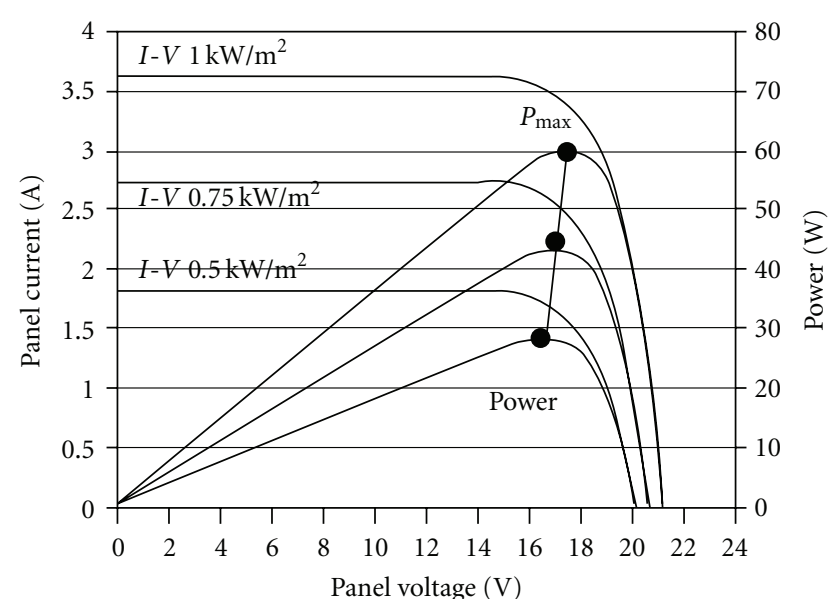

(a)

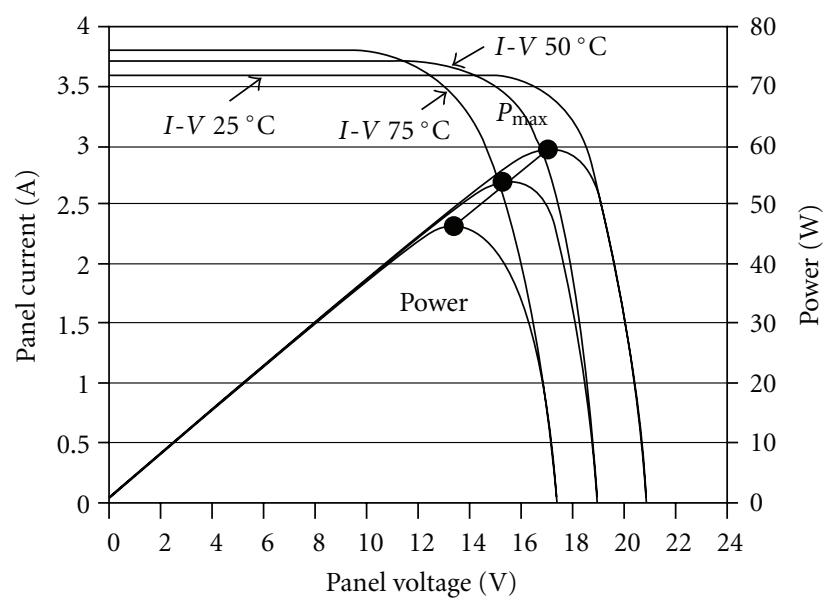

(b)

FIGURE 1: (a) and (b). Solar panel $I-V$ curves versus solar irradiance and temperature variations.

Many papers have been published regarding more efficient use of a solar panel in photovoltaic systems. Some of them only have proposed maximum power point tracking systems to gain more generated output power [1-13]. Some others have used sun-tracking controller in order to increase the incident solar irradiance on solar panels [14-16].

In this research, a simultaneous combination of the two mentioned methods is implemented. Therefore, the solar panel is placed on its best orientation toward the sun, and its maximum output power will be attained. In this way, two separate controllers are required to perform the tasks of sun and maximum power point tracking. Fuzzy-based algorithms are selected for the mentioned controllers because of its high compatibility with nonlinear systems. The fuzzy theory based on fuzzy sets and fuzzy algorithms provides a general method of expressing linguistic rules so that they can be processed quickly. The maximum power point tracking fuzzy controller defines the proper duty cycle of a converter to track the maximum power point using $d P / d I$ and its variations $\Delta(d P / d I)$ as their inputs $[3-9,13]$. Sun tracking fuzzy algorithm uses a proper sensor to track the sun position as described in Section 3.2.

The rest of paper is organized as follows; Section 2 presents the system descriptions. It talks about the employed system's components to implement the proposed algorithms. The fuzzy-based maximum power point tracking and sun tracking algorithms are stated in Section 3. Moreover, rules and membership functions of the fuzzy algorithms are expressed in this section. Section 4 is devoted to $I-V$ curve extraction of the solar panel. It also describes the nonlinear load that is used for $I-V$ curve extraction uniformly. Section 5 describes experimental results for fuzzybased maximum power point tracking and sun tracking algorithms and their combination. A comparison between results provided by fuzzy technique and results provided by other techniques such as incremental conductance and perturbation \& observation is also expressed in this section. Section 6 ends the paper through a conclusion.
TABLE 1: The solar panel specifications.

\begin{tabular}{lcc}
\hline Specifications & Value & Dim \\
\hline Weight & 6 & $\mathrm{Kg}$ \\
Dimensions & $977 \times 462 \times 11$ & $\mathrm{~mm}^{3}$ \\
Ns & 13 & - \\
Np & 5 & - \\
Voc & 20.5 & $\mathrm{~V}$ \\
Isc & 2.98 & $\mathrm{~A}$ \\
Pmax & 45 & $\mathrm{~W}$ \\
\hline
\end{tabular}

\section{System Description}

A block diagram of the proposed system is shown in Figure 2. The system is composed of a microcontroller board (connected to PC), a flyback DC-DC converter, motors driver board, and other supplementary circuits. Tracking the sun is performed by changing the solar panel orientation in horizontal and vertical directions through the control of two DC motors. A portable pyraometer and thermometer are used for online measurement of the environmental conditions: solar irradiance and temperature. The flyback DC-DC converter is used to track the solar panel maximum power point. The converter duty cycle is adjusted in a manner that the maximum solar panel output power is extracted based on load profile in each environmental condition.

The system is able to measure, control, and monitor all parameters, which are needed to implement the mentioned fuzzy-based algorithms. A polycrystalline silicon solar panel with specifications indicated in Table 1 is used for theoretical and experimental analysis.

2.1. Flyback Topology. A switching converter is required to maintain a solar cell's operating point in its maximum power point. In this research, a flyback converter is utilized to fulfill the task. The advantage of using this kind of converter is the 


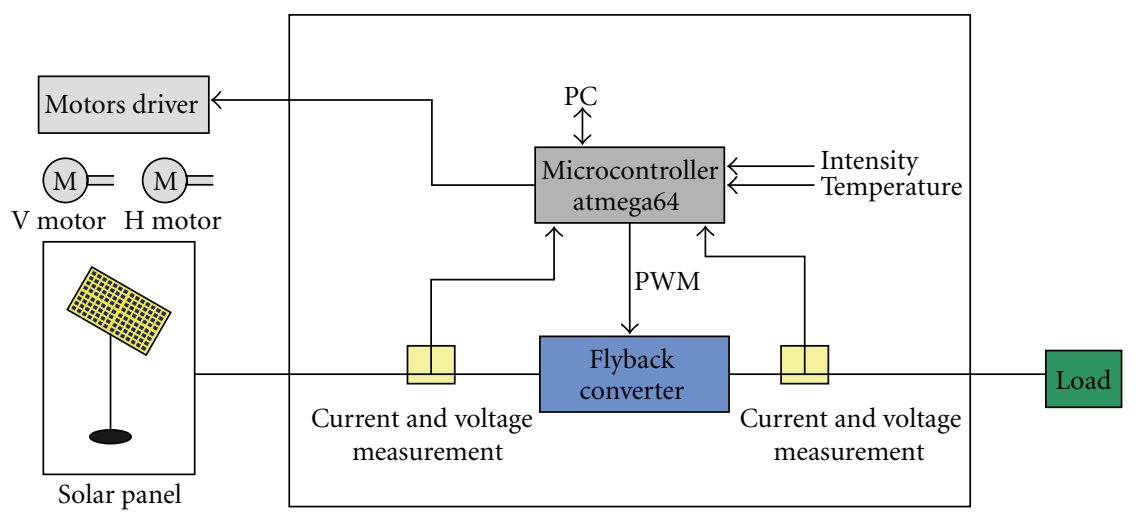

FIgURE 2: The proposed system block diagram.

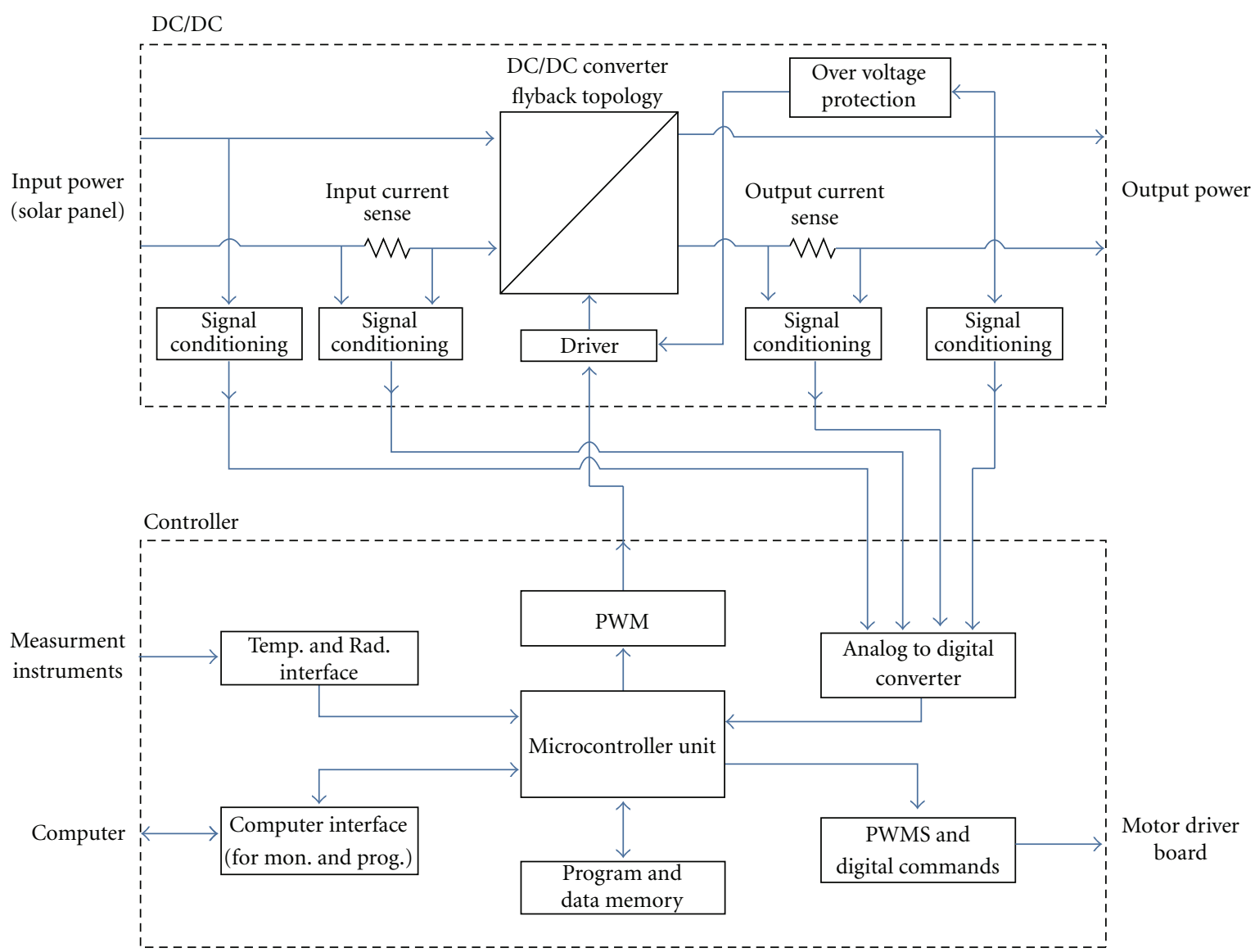

FIGURE 3: The detailed proposed system block diagram.

isolation of its input and output. In addition, fundamental criteria of choosing suitable topology for the required DCDC converter in the mentioned application are

(i) the range of input and output voltage which requires a boost converter (why buck topology is not chosen),

(ii) ability of controlling output power (why boost topology cannot be chosen is the existence of a direct path between its input and output), (iii) simplicity and no complexity (why push-pull topology is not chosen).

Figure 3 shows the connection between the microcontroller and the flyback converter. A flyback converter can modify the input current of the solar panel by changing the pulse width (duty cycle), while in boost converter, input current cannot be less than a specific value. Even when the switch is completely open, a current path exists from its input to output. Furthermore, commands and PWM 


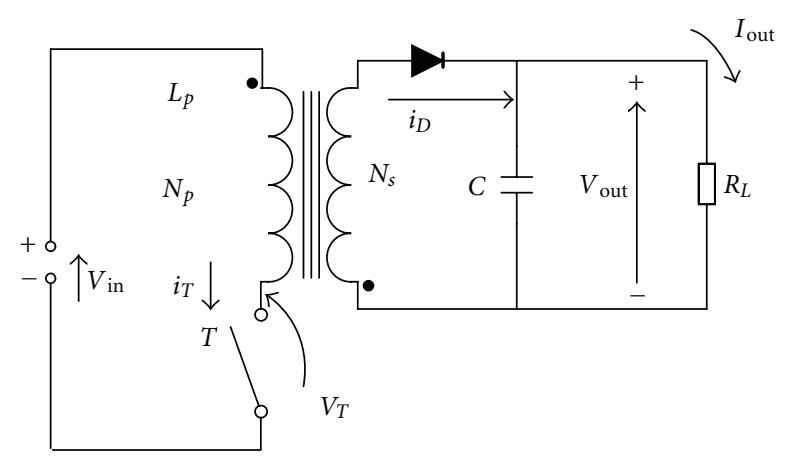

Figure 4: The used flyback topology.

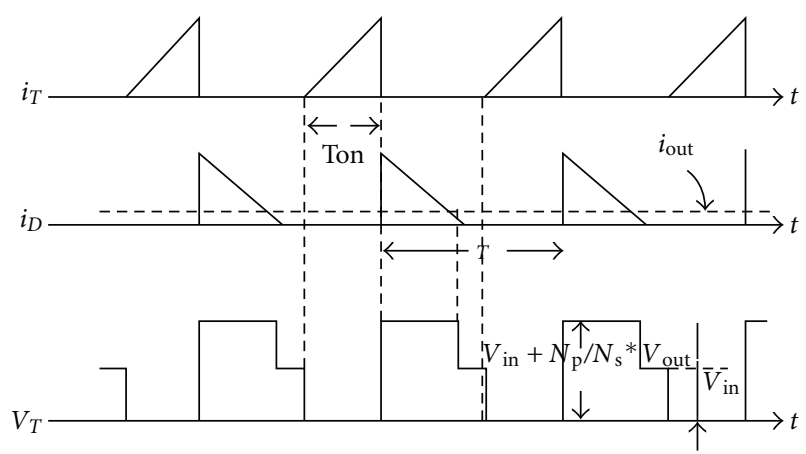

FIGURE 5: The switch current and voltage waveforms, primary and secondary circuit currents.

pulses needed to control the DC motors are provided by the microcontroller to track the sun.

Figure 4 presents the used flyback topology. The operation of the circuit can be studied in two periods. When the switch is on, the energy originated from passing the current in the primary circuit is stored and when the switch is off, the stored energy in the core is transmitted through the diode to the output capacitor. In conduction period of the output diode, the current waveform in the secondary is reduced with a constant slope until it reaches zero. After that until the transmitted energy to the output capacitor is providing the load demand, the switch remains off and then the mentioned cycle is repeated (Figure 5).

Current $i_{T}$ has a direct relation with the duty cycle of the converter. The microcontroller board controls the operating point of the solar panel with modifying the pulse width of the flyback converter. A brief procedure description of maximizing the output power of the solar panel is presented in the following. First, temperature and irradiance are measured, and then two separate fuzzy algorithms are performed simultaneously for sun tracking and maximum power point tracking. Moreover, each several minutes the $I-V$ characteristic of the solar panel is scanned to determine the real value of the solar cell's maximum power.

2.2. Flyback Design Considerations. Figure 6 Shows the schematic circuit of the flyback converter used in this

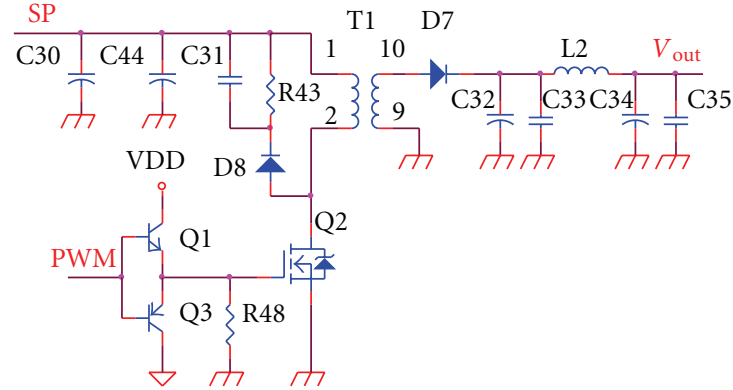

FIgURE 6: The flyback converter's schematic.

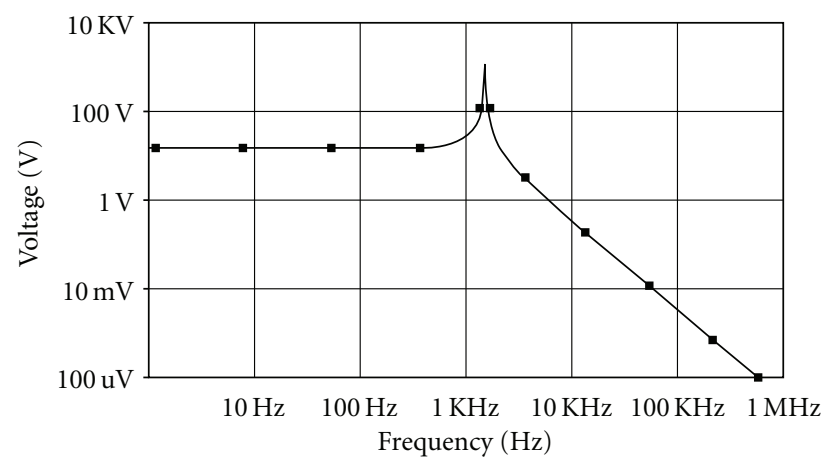

FIGURE 7: frequency response of output filter.

research and it includes the following components:

(i) main circuit of the flyback converter including T1, Q2, D7, C32, C33,

(ii) snubber circuit including D8, R43, C31,

(iii) switch driver (Q2) including Q1, Q3, R48,

(iv) output filter including L2, C34, C35.

When switch Q2 is on, energy is stored in the transformer's inductor and then when the switch becomes off, by conducting the output diode this energy is transferred to the load. Therefore, the base of transformer's calculation is the stored energy in its inductor which is computed as follows (with assumption of $I_{\mathrm{sc}}=1.2 I_{p}$ ):

$$
\begin{aligned}
W & =0.5 L_{P} I_{\text {SC }}^{2}=0.5(1.2)^{2} L_{P} I_{P}^{2}=0.72\left(\frac{V_{\text {in }} \times t_{\text {on }}}{I_{P}}\right) I_{P}^{2} \\
& =0.72 V_{\text {in }} \times t_{\text {on }} \times\left(\frac{I_{a} \times 2 T}{t_{\text {on }}}\right)=1.44 P_{i} T .
\end{aligned}
$$

By assuming efficiency $80 \%$,

$$
W=\frac{1.44 P_{0} \times T}{\eta}=1.8 P_{0} \times T \approx 2 P_{0} \times T .
$$




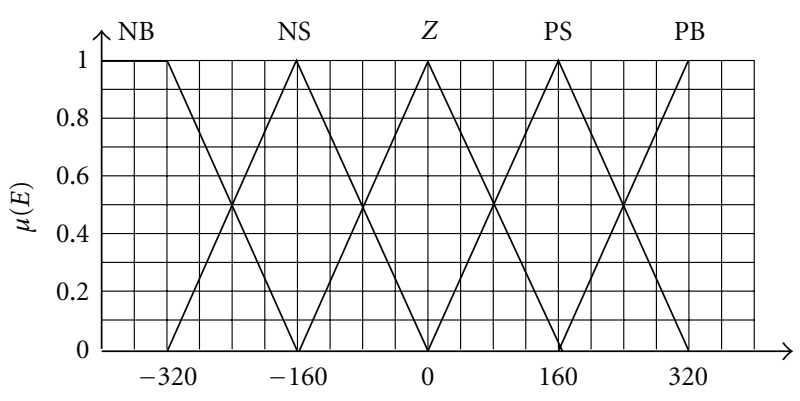

(a)

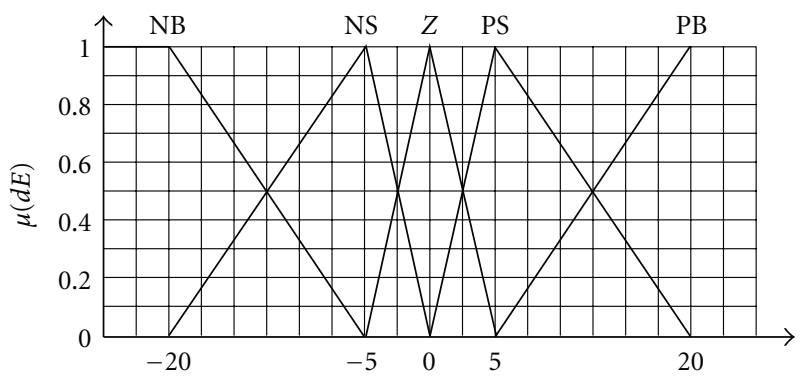

(b)

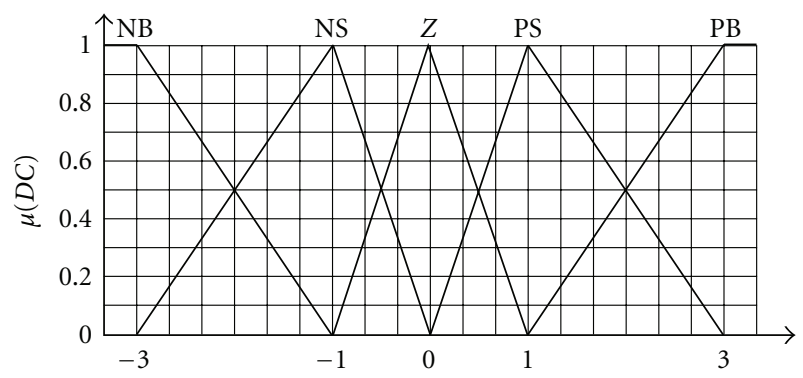

(c)

Figure 8: (a) Membership function plots of E, (b) Membership function plots of dE, (c) Membership function plots of converter duty cycle.

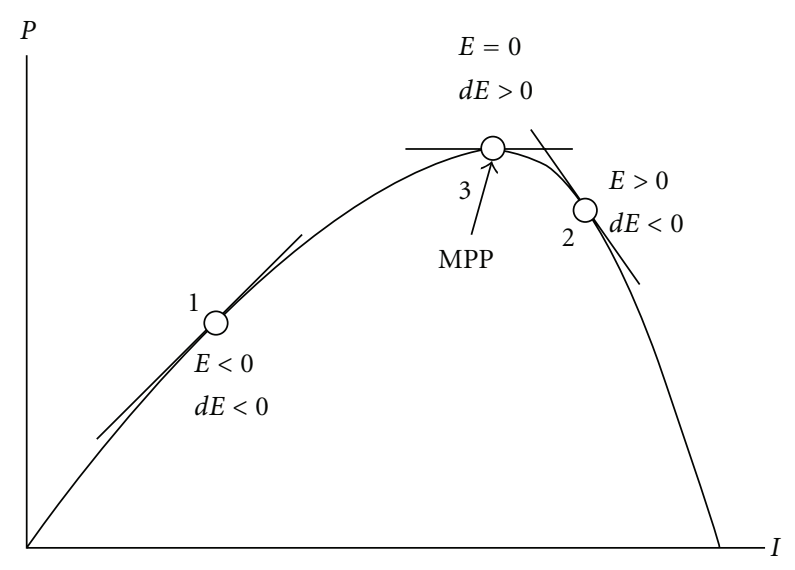

FIGURE 9: Power versus current curve of a solar panel.

In addition, it is known that

$$
\begin{aligned}
W & =\int F d \varphi=\int(H \times d l) \times(A \times d B) \\
& =\int A \times l \times\left(\frac{B}{\mu}\right) \times d B=A \times l \times \frac{B_{m}^{2}}{(2 \mu)} .
\end{aligned}
$$

An air gap is considered to prevent core saturation (in this way, small cores can be used). Since the air gap's reluctance is much larger to the core's reluctance, the core's reluctance can be ignored in calculations.

Relation (2) and (3) are used to calculate the air gap. With assumption of $f=32 \mathrm{kHz}$ and $P_{o}=36 \mathrm{~W}$ (product of the solar panel output power and efficiency of the converter) and

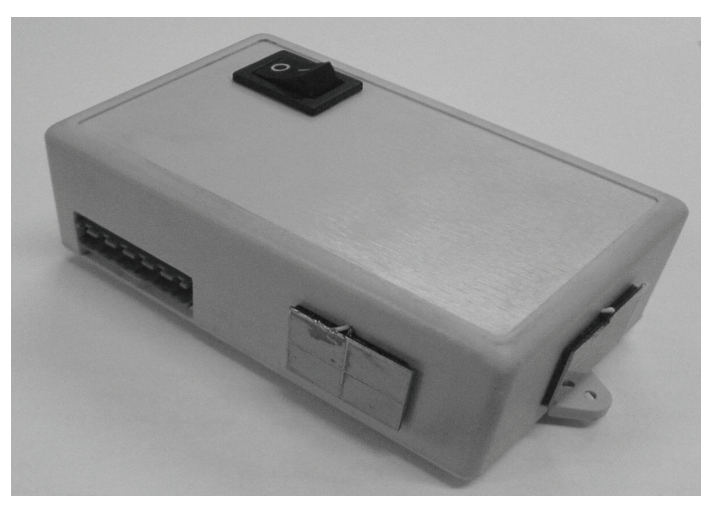

FIGURE 10: The proposed sun-tracking sensor.

by using (2), the value of $\mathrm{W}$ is obtained $2.16 \mathrm{~mJ}$. Then with assumption of $B_{m}=0.25 \mathrm{~T}$ and using (2) and (3), the value of air gap for ferrite core EE2525 with cross section of $55 \mathrm{~mm}^{2}$ is approximately obtained $1.6 \mathrm{~mm}$.

Now the inductance of transformer primary winding can be specified. For this purpose, the worst case should be considered which is minimum value of the input voltage and maximum load (in this case, the pulse width of PWM is maximum) again, by using the relation of stored energy in an inductor, we have

$$
\begin{aligned}
P_{o} & =\eta \times P=\eta \times\left(0.5 L_{p} I^{2}\right)=0.4 L_{P}\left(\frac{I_{P} \times 2 T}{\overline{t_{\mathrm{on}}}}\right) \\
& \left.=0.4 L_{P}\left(\frac{V_{\mathrm{in}} \overline{\overline{\mathrm{on}}}}{L_{P}}\right) \times \frac{2 T}{\overline{t_{\mathrm{on}}}}\right)^{2},
\end{aligned}
$$




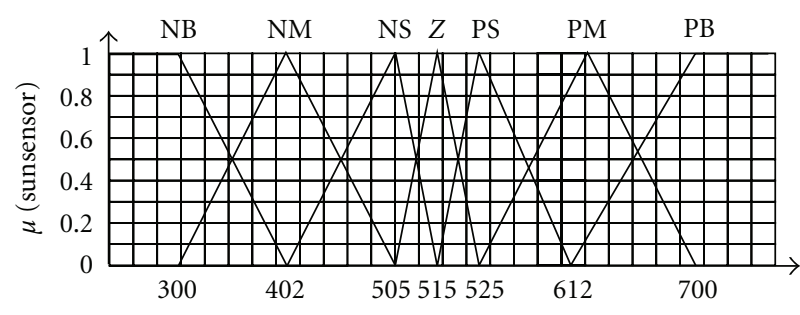

(a)

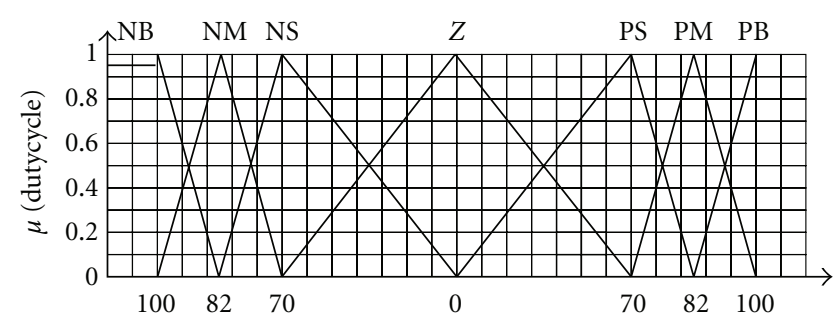

(\%)

(b)

FIGURE 11: (a), (b). Membership function of sun-tracking subsets.

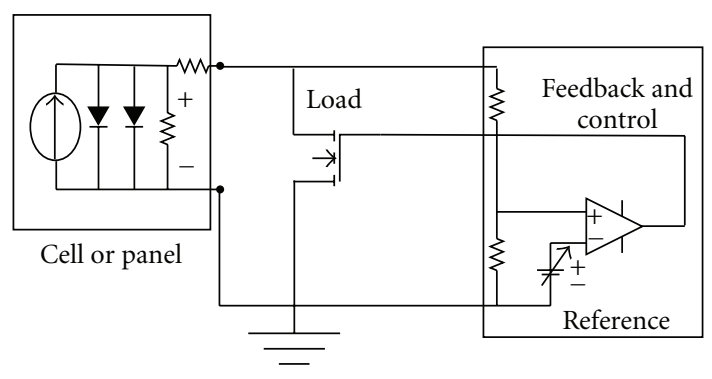

Figure 12: The proposed nonlinear electronic load.

$$
L_{p}={\underline{\text { in }^{2}}}^{2} \times \frac{\left(\overline{t_{\mathrm{on}}}\right)^{2}}{\left(2.5 P_{o} T\right)} .
$$

If $t_{\text {on }}$ is assumed half of $T$, by substituting in (5), the amount of $L_{p}$ is calculated $20 \mu \mathrm{H}$. Now, by use of (6), the turn numbers of primary coil can be specified.

$$
N^{2}=L \times \frac{g}{\left(\mu_{0} \times \mathrm{A}\right)} .
$$

Considering core specification and the calculated value of air gap, the number of the primary winding turns is specified 22 . To determine the number of the secondary coil turns, it is necessary to know the transformer turns ratio, which can be calculated as follows. If $\Delta I^{+}$denotes current variations when the switch is on and $\Delta I^{-}$denotes current variations when the switch is off, by using the relation of voltage and current of an inductor it can be obtained:

$$
\begin{gathered}
\Delta V=\frac{L \times \Delta I^{+}}{\overline{t_{\mathrm{on}}}} \Longrightarrow \Delta I^{+}=\left(V_{\mathrm{in}}-V_{\text {sat }}\right) \times \frac{\overline{t_{\mathrm{on}}}}{L}, \\
\Delta V=\frac{L \times \Delta I^{-}}{\overline{t_{\mathrm{off}}}} \Longrightarrow \Delta I^{-}=\left(\frac{N_{p}}{N_{s}}\right) \times\left(V_{o}+V_{f}\right) \times \frac{\overline{t_{\mathrm{off}}}}{L} .
\end{gathered}
$$

In above relations, $V_{\text {in }}$ is input voltage, $V_{\text {sat }}$ voltage drop of the switch in saturation state, $\overline{t_{\mathrm{on}}}$ maximum pulse width of PWM (minimum of input voltage and maximum load), $t_{\text {off }}$ the time that switch is off $t_{\text {off }}=T-t_{\text {on }}, N_{p} / N_{s}$ transformer turns ratio, $V_{o}$ output voltage, and $V_{f}$ diode's forward voltage. Because current peaks are equal in the both mentioned situations,

$$
\left(\underline{V_{i}}-V_{\mathrm{sat}}\right) \times \overline{t_{\mathrm{on}}}=\left(\frac{N_{P}}{N_{s}}\right) \times\left(V_{o}+V_{f}\right) \times t_{\mathrm{off}}
$$

By assuming $V_{\text {sat }}=V_{f}=1 \mathrm{~V}$, transformer turn ratio will be 0.38 . So the number of the secondary winding turns is calculated 58. In order to select the output diode, the maximum power and voltage that it can tolerate, should be calculated. The maximum voltage drop of the diode is equal to:

$$
V_{d \max }=\frac{V_{\text {in max }}}{N}+V_{o}=\frac{20}{0.38}+36=88.6 .
$$

By considering a safe margin, fast diodes with $100 \mathrm{~V}$ forward voltage can be selected, but maximum power of the diode can be calculated as follows:

$$
P_{d \max }=I_{\mathrm{orms}} \times V_{f} \times\left(1-\overline{t_{\mathrm{on}}}\right)=1 \times 1 \times(1-0.5)=0.5 .
$$

In computing the output capacitor, this point is needed to be considered that it should be able to provide load current when the input switch is off; therefore,

$$
\begin{aligned}
C_{o} & =\frac{I_{o} \times\left(1-\overline{t_{\mathrm{on}}}\right)}{\Delta V_{o}}=\frac{1 \times(1-0.5) \times 32 \times 10^{-6}}{0.1} \\
& =160 \mathrm{uF} \approx 220 \mathrm{uF} .
\end{aligned}
$$

2.2.1. Selection of Switches and Their Driver Circuits. Drain voltage of MOSFET Q2 reaches the value of $V_{i}+\left(N_{p} / N_{s}\right) V_{o}$ which equals $34 \mathrm{~V}$. If the amplitude of switch's spike is considered $30 \%$ of the mentioned value and a safe margin of $25 \%$ is taken into account, the output voltage of $58.5 \mathrm{~V}$ or approximately $60 \mathrm{~V}$ can be tolerated. The maximum current of the switch which is the inductor's current is approximately equaled to $10.6 \mathrm{~A}$. Therefore, by considering the safe margin, the switch should tolerate $13.25 \mathrm{~A}$. According to the mentioned limitations, IRFZ44 MOSFET is selected, because its maximum drain-source voltage is $60 \mathrm{~V}$ and its drain current is $50 \mathrm{~A}$. In addition, its drain-source resistance is $28 \mathrm{~m} \Omega$, which reduces the switch thermal loss.

2.2.2. Calculation of Snubber Circuit. When gate's voltage of MOSFET Q2 becomes zero, the current is not immediately stopped and because of increasing of drain voltage to $V_{\text {drain }}=$ $\left(N_{p} / N_{s}\right) \times V_{o}+V_{\mathrm{DC}}=0.38 \times 40+20=35.5$, MOSFET thermal loss is considerably increased. The amplitude of drain voltage should be considered $30 \%$ more and its reason 


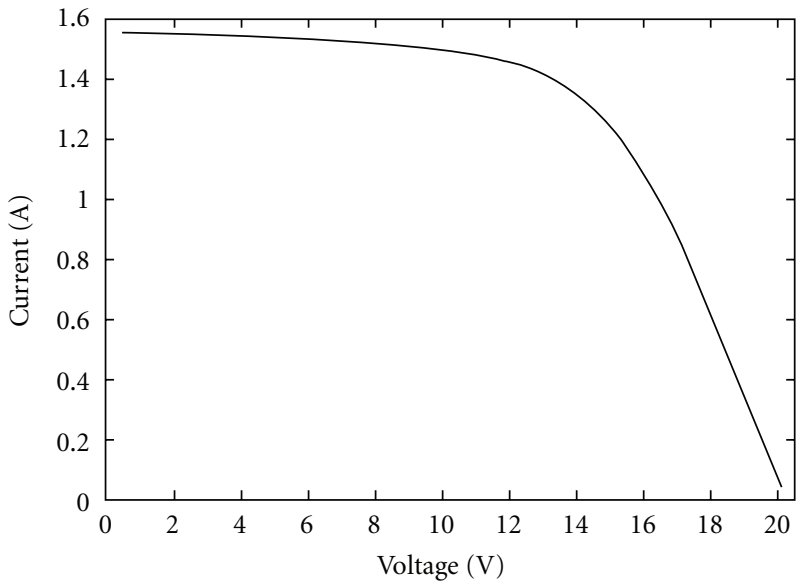

(a)

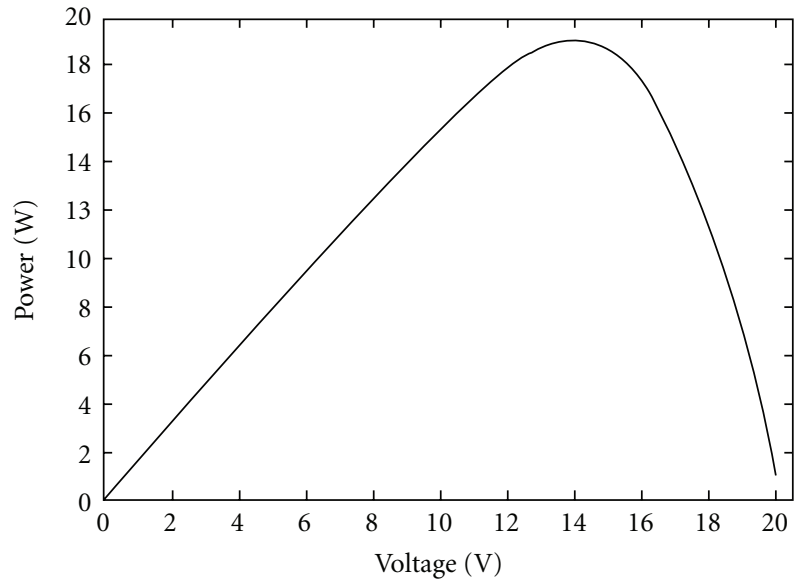

(b)

Figure 13: (a) and (b) A typical extracted solar panel $I$ - $V$ curve.

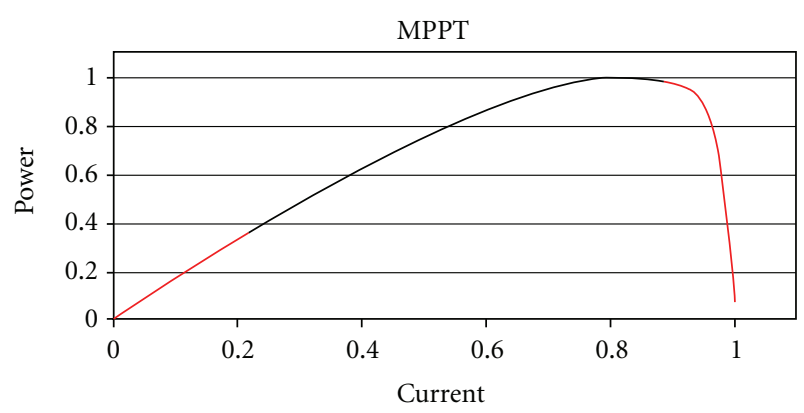

FIGURE 14: The Variations of solar panel operating point.

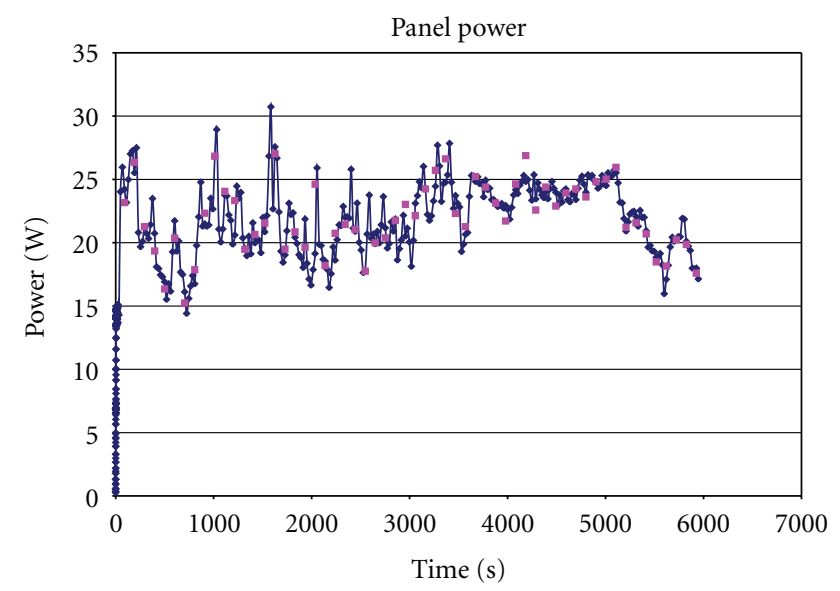

FIGURE 15: solar panel maximum output power.

is the spikes produced by MOSFET's switching. Hence, drain voltage approximately reaches $48 \mathrm{~V}$. Although spikes appear in a short time, this time is so long in comparison with the time, which MOSFET turns off. So adding a snubber circuit like the one presented in Figure 6, (D8, C31, R43) can restrict drain voltage to input voltage $\left(V_{\text {in }}\right)$ during MOSFET turning off. By turning off the switch and just by exceeding

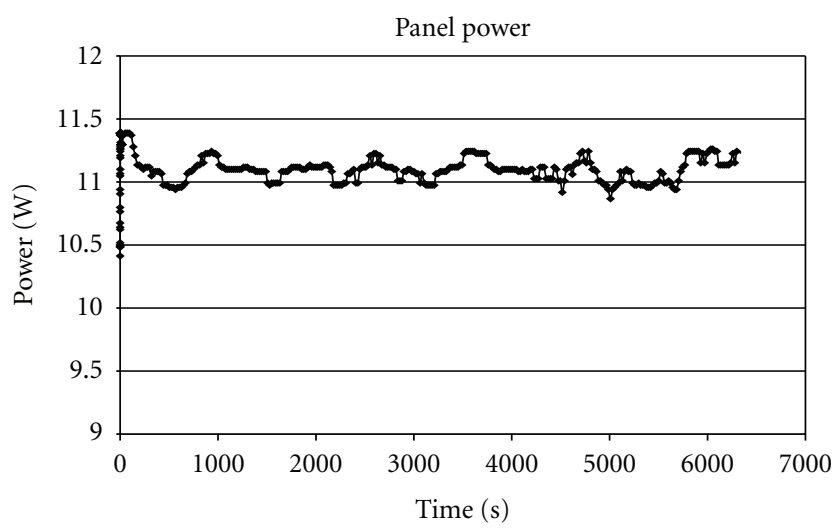

FIGURE 16: Solar panel output power.

drain voltage from the value of input voltage, diode D8 starts to conduct and capacitor C31 begins to charge. The amount of capacitor should be selected in a manner which its complete charge take place after turning off the switch. Resistance R43 should also exhaust the stored energy in capacitor before further switch's turning on. While MOSFET turns off, switch's current equals $I_{p}$ and drain voltage equals $\left(N_{p} / N_{s}\right) \times V_{o}+V_{\text {DC }}$. On the other hand, MOSFET's truing off duration is approximately 0.1 us according to MOSFET IRFZ44 data sheet. Therefore, capacitance can be estimated as follows:

$$
C=\frac{I_{P} \times t_{f}}{2 \times\left(V_{\text {drain }}-V_{\text {in }}\right)}=\frac{10 \times 0.1 \times 10^{-6}}{2 \times(48-15)}=15 n F .
$$

By presuming $3 \mathrm{RC}=t_{\mathrm{on}}$, the value of $\mathrm{R} 43$ is calculated $330 \Omega$.

2.2.3. Output Filters. The output filter should not allow the noises produced by switching reach the loads. Frequency of switching of the converter is $32 \mathrm{kHz}$ so the filter's elements should be chosen in a manner which reduces the amplitude 


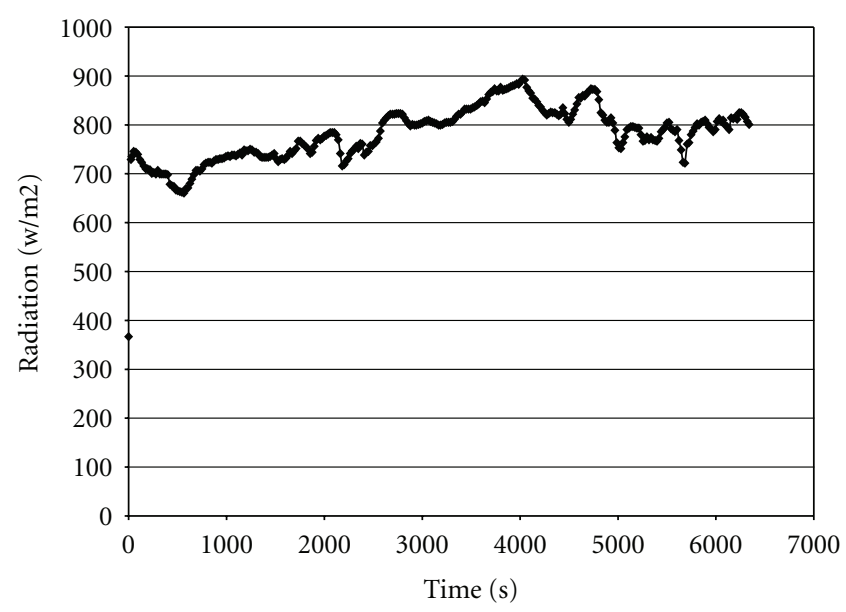

(a)

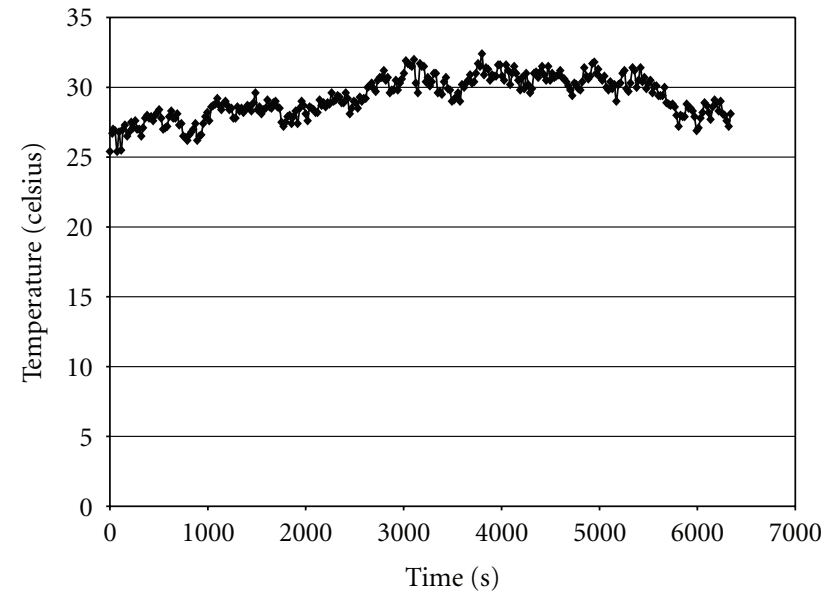

(b)

Figure 17: (a) and (b). Solar irradiance and temperature variations.

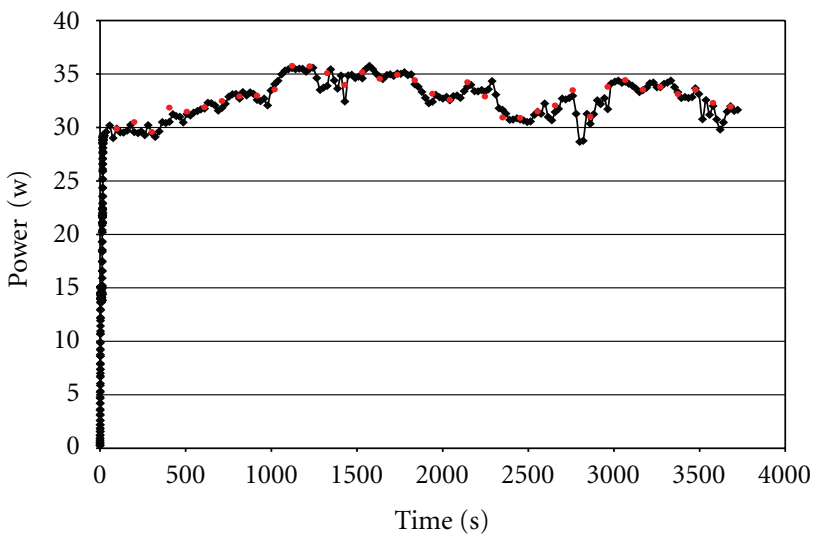

FIgURE 18: Solar panel output power.

of noise. Selected filter for the used converter is $\pi$ type. Figure 7 shows the frequency response of the filter by choosing C34 = C32 $=220 \mathrm{uH}$ and $L=50 \mathrm{mH}$.

\section{The Fuzzy Algorithms}

In this section, the details of fuzzy-based maximum power point tracker and fuzzy-based sun tracker are fully described.

\subsection{Fuzzy-Based Maximum Power Point Tracking. Maximum} power point tracking can be carried out by adjusting the duty cycle of the flyback converter. Fuzzy logic is used as one of the several methods to track the maximum power point of a solar panel because of its good stability and quick response [3-9]. In this method, the input variables of the fuzzy controller are $d P / d I$ and its variations $\Delta(d P / d I)$. The fuzzy controller calculates $E=(d P / d I)(k)$ and $d E(k)$ using measured solar panel input power and current as stated in (13) and (14).

$$
E=\frac{d P}{d I}(k)=\frac{P(k)-P(k-1)}{I(k)-I(k-1)},
$$

TABLE 2: Maximum power point tracking fuzzy rule base.

\begin{tabular}{lccccc}
\hline & & \multicolumn{2}{c}{$\mathrm{dE}$} & & \\
$E$ & $\mathrm{NB}$ & $\mathrm{NS}$ & $Z$ & PS & PB \\
\hline NB & NB & NB & NB & $Z$ & $Z$ \\
NS & NS & NS & NS & $Z$ & $Z$ \\
$Z$ & NS & $Z$ & $Z$ & $Z$ & PS \\
PS & $Z$ & $Z$ & PS & PS & PS \\
PB & $Z$ & $Z$ & PB & PB & PB \\
\hline
\end{tabular}

$$
d E(k)=E(k)-E(k-1)
$$

Inputs and output of the fuzzy controller are expressed by five linguistic variables: PB (positive big), PS (positive small), ZO (zero), NS (negative small), and NB (negative big). Fuzzy controller membership functions are shown in Figures 8(a), $8(\mathrm{~b})$, and $8(\mathrm{c})$. Triangle membership function subsets are chosen and membership functions boundaries are expressed.

25 fuzzy rules are used as stated in Table 2 [4]. Figure 9 presents power versus current curve of a solar panel and three operation points on it.

Range of membership functions is specified based on the panel's specification, relations (13) and (14), and empirical experiments. According to the executed empirical experiments, membership functions and their ranges are finalized so that membership function of $\mathrm{dE}$ is different form membership function of E. Moreover, output membership function is based on center of maximum technique and empirical experiments for data defuzzification.

3.2. Fuzzy-Based Sun Tracking. As it was mentioned, several sun-tracking systems have been proposed and implemented [14-16]. Some of them are based on using the data of whole one-year sun trajectory. Some others generally use a sunsensor to track the sun. Tracking the sun can be fulfilled by evaluation of open circuit voltage, short circuit current, solar irradiance, instant output power, or maximum output power 


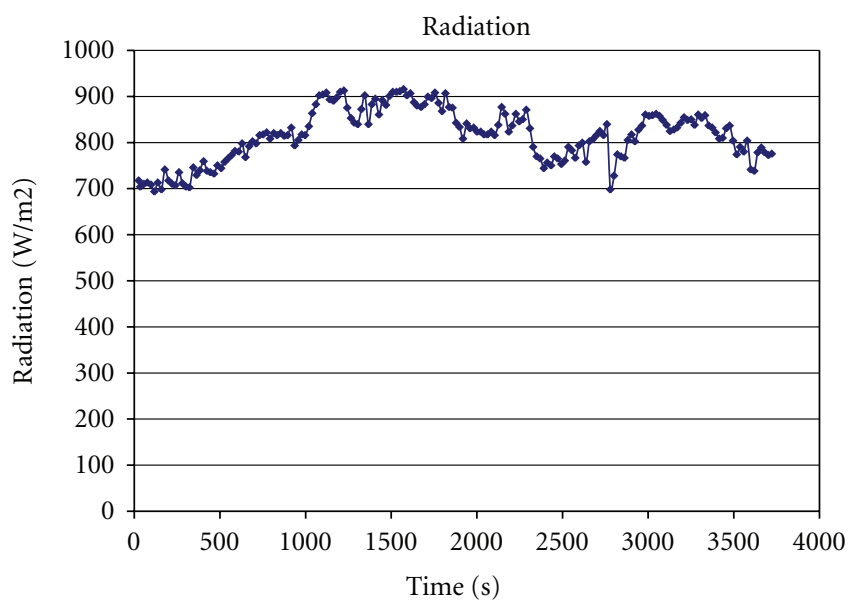

(a)

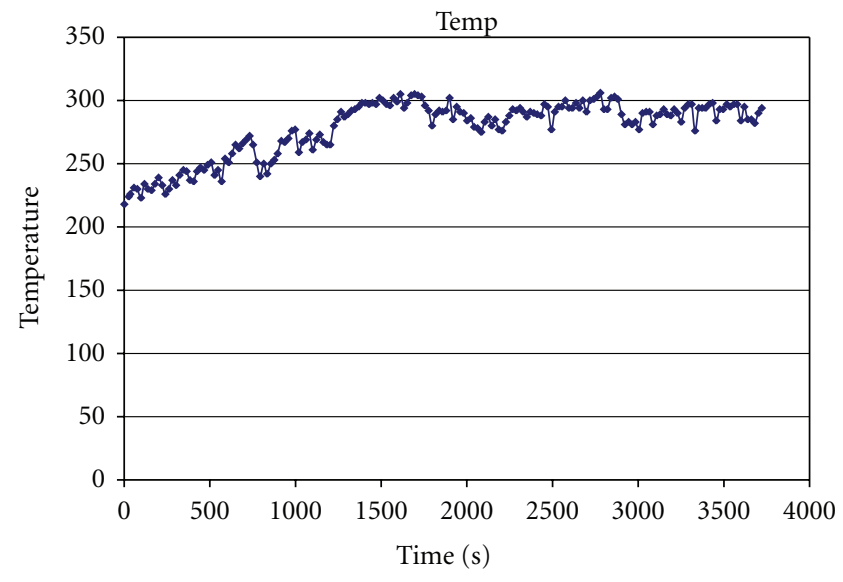

(b)

Figure 19: (a) and (b) Solar irradiance and temperature variations.

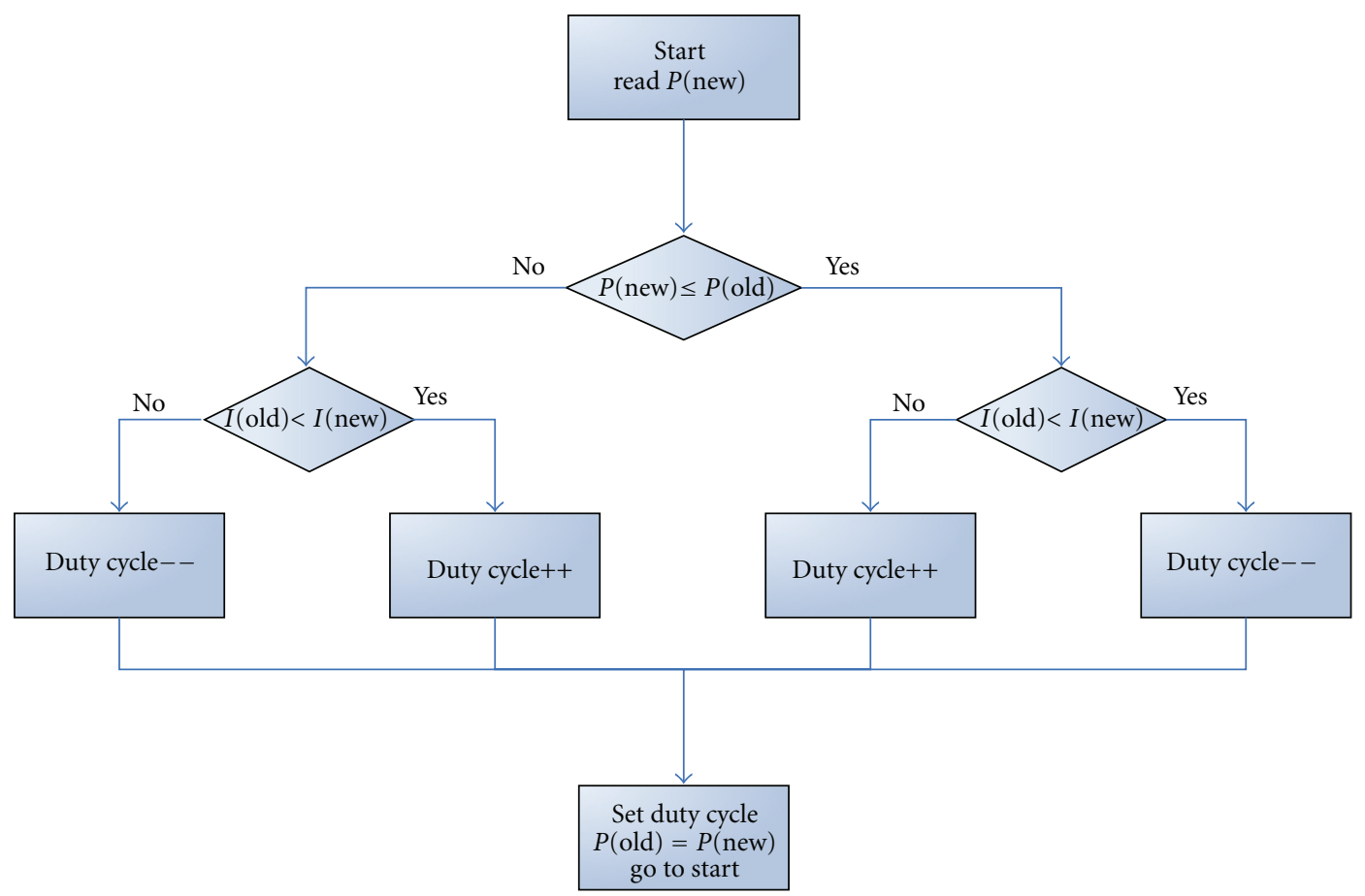

FIGURE 20: The incremental conductance algorithm.

of a solar panel. In this research, two similar fuzzy controllers are separately used to track the sun in horizontal and vertical directions. Two DC motors control the orientation of the solar panel through the designed motors driver board.

Figure 10 shows the proposed sun-sensor used to locate the sun position. As seen in Figure 10, four silicon solar cells have been placed on four lateral sides of a cubic box $(J 1, J 2$, $J 3$, and J4). The voltages of the opposite sides are subtracted as stated in (15).

$$
\text { Sun1 }=V(J 1)-V(J 2), \quad \text { Sun2 }=V(J 3)-V(J 4) .
$$

Sun1 and Sun2 were used as the inputs of the fuzzy controllers to track the sun. If the solar radiation level on the solar cells is similar, then the value of Sun1 and Sun2 will be zero. It means that the sun radiates on the solar panel vertically as is desired. Figure 11 shows membership functions of fuzzy-based sun tracker subsets. Table 3 shows seven fuzzy rules used in the two controllers [14].

Calibration of the designed sensor is necessary for tracking the sun position accurately. A controllable lighting system is considered and four solar cells are calibrated. Light is radiated on each solar cell and the value of Sun1 and 


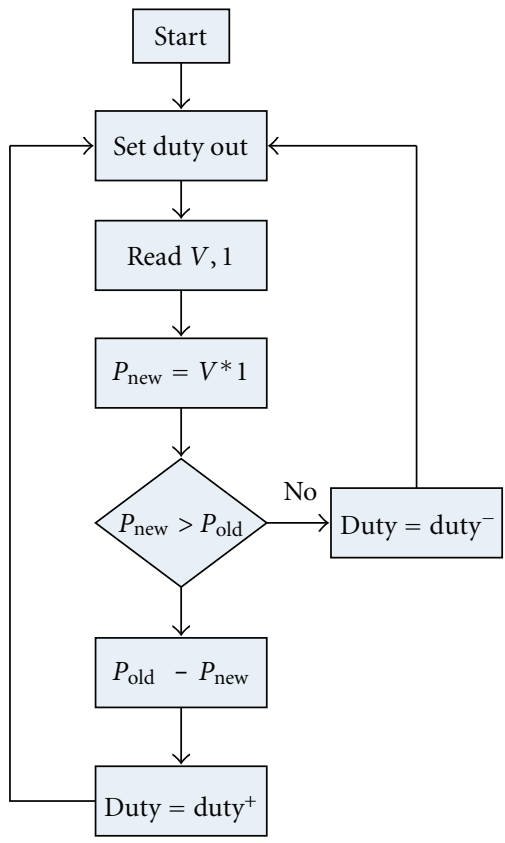

FIgURE 21: The perturbation and observation algorithm.

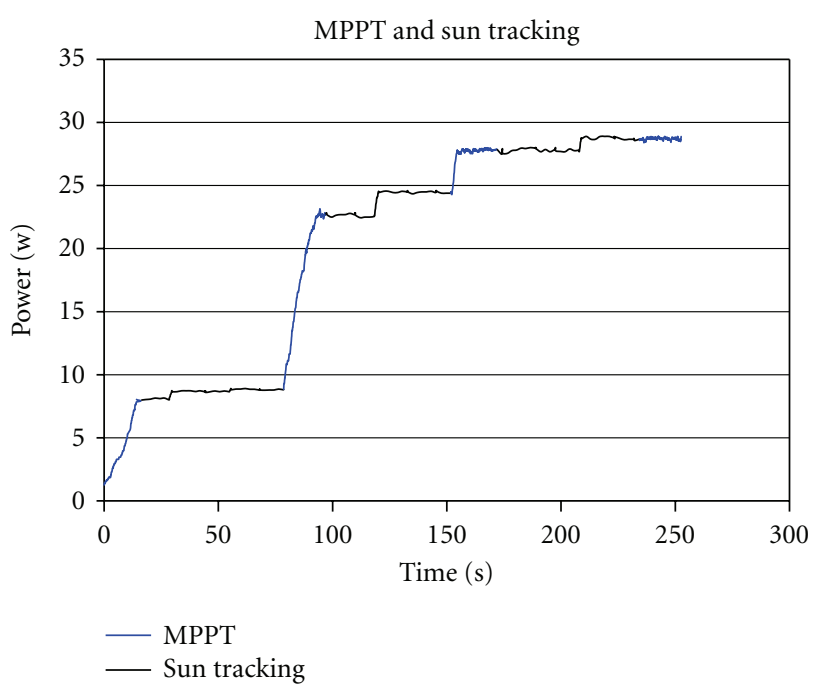

Figure 22: Panel's power variations during Simultaneous execution of the two mentioned algorithms.

TABLE 3: Sun tracking fuzzy rule base.

\begin{tabular}{llllllll}
\hline Sun sensor & $N B$ & $N M$ & $N S$ & $Z$ & $P S$ & $P M$ & $P B$ \\
Duty cycle & NB & NM & NS & $Z$ & PS & PM & PB \\
\hline
\end{tabular}

Sun 2 are measured by the proposed system. This procedure is performed four times for all solar cells, respectively $(J 1, J 2$, $J 3$, and J4). The microcontroller system reads the amount of the cell voltage: Sun 1 and Sun2 in each step of the calibration procedure. Table 4 presents some example values in different light intensity in laboratory. Finally, the employed sensor

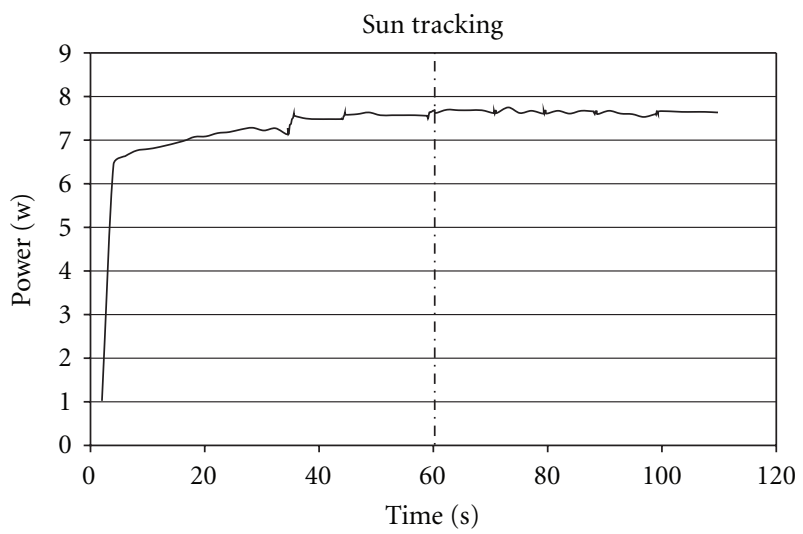

FIGURE 23: Output power variations during sun tracking.

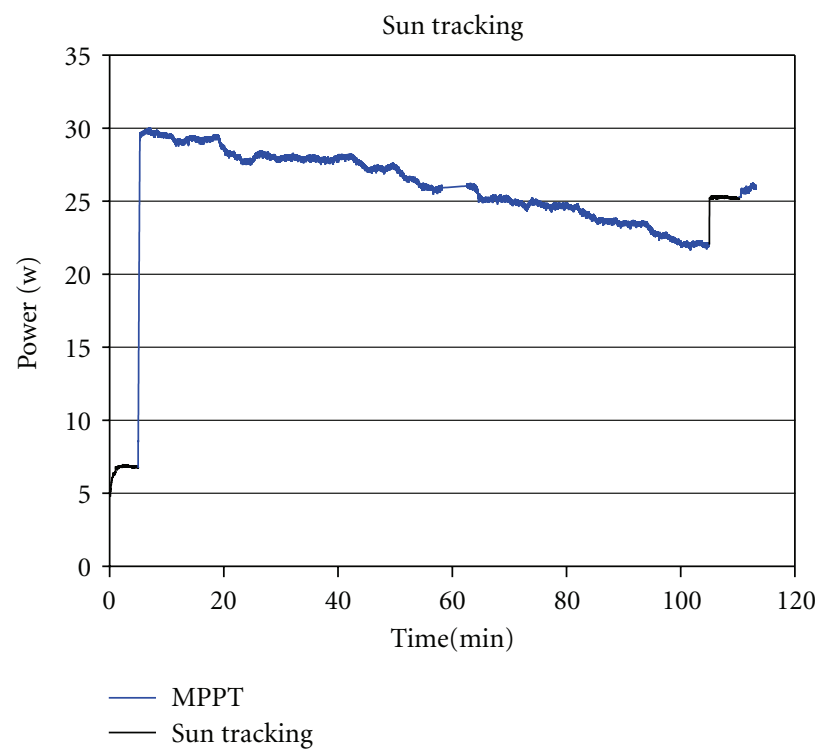

FIGURE 24: Long-term sun tracking and MPP Tracking.

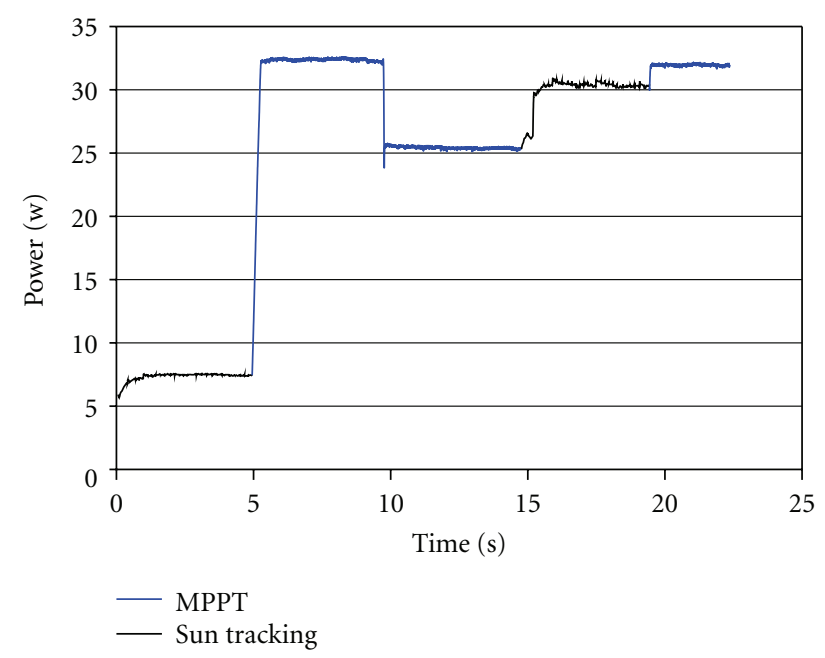

FIGURE 25: Reaction of system to fast movement of the sun position. 
TABLE 4: Voltage variation of J2 cell.

\begin{tabular}{lcc}
\hline$J 2$ (Volt) & Sun sensor1 & Sun sensor2 \\
\hline 0.5 & 313 & 517 \\
0.4 & 313 & 517 \\
0.3 & 327 & 517 \\
0.2 & 390 & 517 \\
0.1 & 450 & 517 \\
0 & 514 & 517 \\
\hline
\end{tabular}

can be calibrated and be used for fuzzy-based sun-tracking algorithm.

The range of the input and output membership functions in the fuzzy sun tracker is specified based on mathematic relation (15), empirical experiments on the manufactured sensor, and sun-tracking system.

\section{The $I-V$ Curve Extractor}

Solar panel $I-V$ curves have an important role in design of photovoltaic systems. To verify the fuzzy-based maximum power point tracking, solar panel $I-V$ curves are needed. In order to attain a solar panel $I-V$ curve, it is sufficient to change the panel current between zero (open-circuit) and its maximum value (short-circuit) continuously or step by step. Then the characteristic curves can be obtained by measuring the corresponding voltages and currents. Hence, a variable load is required across the panel output ports. Since the solar panel $I-V$ curves are nonlinear, the load variation profile has a significant impact on the precision of the extracted curves, that is, if the load resistance varies linearly, the measured points will have higher density near the ends (Isc or Voc) than the other parts of the curves. This nonuniformity of the extracted $I-V$ curves points decreases the accuracy of the maximum power point tracking algorithm so an electronic load with nonlinear profile must be selected as discussed in below.

4.1. Electronic Load with Nonlinear Profile. Figure 12 shows the schematic diagram of the proposed electronic load. The drain-source resistance of a MOSFET is used as a variable load, controlled by its gate-source voltage [17]. The drainsource resistance of a MOSFET has an inverse relation with the gate-source voltage of the MOSFET. This electronic resistance is very suitable to scan the $I-V$ characteristic of a solar panel uniformly.

Figures 13(a) and 13(b) show a typical extracted $I-V$ and $P-V$ curves obtained by the mentioned electronic load in the following conditions: solar irradiance $=500 \mathrm{~W} / \mathrm{m}^{2}$ and temperature $=34.5^{\circ} \mathrm{C}$. As it can be observed, the measured points have a uniform distribution through the entire $I-V$ curve.

\section{Experimental Results}

Based on the established setup, different tests were executed. First, only the fuzzy-based MPPT was applied to the system for 100 minutes. Solar panel $I-V$ curves were required to perform this test. Figure 14 shows the movement of the solar panel operating point in a $P-I$ curve towards its maximum level using the fuzzy maximum power point tracking.

The test was performed in the following conditions: temperature $=36.8^{\circ} \mathrm{C}$ and solar Irradiance $=830 \mathrm{~W} / \mathrm{m}^{2}$. It is observed that the fuzzy-based maximum power point tracking algorithm reached its maximum level after 0.57 seconds, which is a reasonable rate. $I-V$ curves were obtained in different environmental conditions. Solar irradiance, temperature, and maximum output power are extracted for each curve. Figure 15 shows both extracted maximum power points from the $I-V$ curves (continues graph) and measured data (single points).

It is observed that the fuzzy-based controller has tracked the maximum power point during the test period. The decreasing trend of the figure at the end of the test period is because of the sun movement. To overcome the defect, the adjustment of the solar panel orientation should be added to the system. The second test was applying only the fuzzybased sun tracking to the system for 100 minutes. Figure 16 shows the panel output power. Figures 17(a) and 17(b) also show variations of solar irradiance and temperature during this test.

The algorithm was tested in the condition that the angle between solar panel and sun radiation was $80^{\circ}$. A pyranometer and a digital thermometer with 20 seconds intervals measured solar irradiance and panel temperature online. As it can be observed from Figure 16, the output power remained almost constant in spite of the sun movement during the test. The cause of the small fluctuation in output power was the variations of temperature and solar irradiance as shown in Figures 17(a) and 17(b). Since in this test maximum power point tracking was not applied, the maximum extractable output power has not yet achieved. Based on the results of the two mentioned tests, it is expected that the combination of the two methods causes more power delivery as is explained in below.

Figures 18, 19(a), and 19(b) show the results of the mixture of the two mentioned techniques. The solar panel output power is shown in Figure 18. Red points show the solar panel maximum power points extracted from the $I-V$ curves whereas the black points show the measured solar panel output power. It is observed that the mixture of the two mentioned algorithms leads to the maximum power delivery to the load in any environmental conditions. It should be mentioned that to have a reasonable comparison between utilized techniques, measurements should be performed in equal environmental conditions. Therefore, the menstruations were carried out several times in different days to obtain the mentioned purpose, which can be seen from Figures 17 and 19.

In order to compare the implemented technique with other techniques of maximum power point tracking, incremental conductance and perturbation \& observation techniques are executed and compared with the fuzzy technique. Figure 20 shows the flowchart of incremental conductance method. The implementation's results state that 
this algorithm reached maximum power point in $1.92 \mathrm{~S}$ in temperature of $35.8^{\circ} \mathrm{C}$ and irradiance of $820 \mathrm{~W} / \mathrm{m}^{2}$.

Figure 21 shows the flowchart of perturbation and observation algorithm generally. In this research, two-point and three-point methods are carried out. Two-point algorithm carried operating point to maximum power point in $4.36 \mathrm{~S}$ while three-point algorithm to the same in $11.71 \mathrm{~S}$. This difference in reaching maximum power point is because of the numbers of voltage and current measurements in each algorithm.

Other experiments are executed regarding combination of sun and maximum power point tracking, which are expressed as follows. Figure 22 presents the variations of delivered power from the panel during execution of maximum power point tracking and sun-tracking algorithms. Blue parts show power variations during sun tracking and black parts show power variations during maximum power point algorithm. The panel had the horizontal angle of $90^{\circ}$ and vertical angle of $30^{\circ}$ with the sun in beginning of the experiment. As it is seen, in the beginning of the experiment power had the value of $2 \mathrm{~W}$ which is brought to $8 \mathrm{~W}$ by the maximum power point algorithm. Consequently, sun tracking algorithm is activated so the panel obtained a better position and power reached the value of $9 \mathrm{~W}$. Maximum power point tracking was again activated and power reached the value of $23 \mathrm{~W}$.

So that the system, in $250 \mathrm{~s}$, reached the situation which the sun direction is completely perpendicular to the panel and $28 \mathrm{~W}$ power delivered. That amount of power is equal to the maximum generated power, which can be delivered in temperature about $26^{\circ} \mathrm{C}$ and irradiance about $600 \mathrm{~W} / \mathrm{m}^{2}$.

In Figure 23, it can be seen that the panel in $60 \mathrm{~S}$ arrived from its initial state (horizontal angle of $90^{\circ}$ and vertical angle of $30^{\circ}$ with the sun) to its final state (the sun is perpendicular to the panel), then the speed of system to track the sun can be evaluated properly.

Another experiment is executed to show the importance of sun tacking which its result is presented in Figure 24 . In the experiment, sun taking is deactivated for $120 \mathrm{~min}$ while maximum power point tracking was executing. After the mentioned period, although maximum power point tracking algorithm was activated, delivered power reduced $8 \mathrm{~W}$ because of the movement of the sun. While after activating the sun tracking system, delivered power reached its maximum value, which was $25 \mathrm{~W}$. (The reason of reduction in maximum power was irradiance drop near the sunset)

A similar experiment was performed to show the speed of sun-tracking. In the experiment, sun tracking algorithm for $5 \mathrm{~min}$ and maximum power point tracking algorithm for $10 \mathrm{~min}$ was successively executed. Figure 25 shows the results of the experiment. In this experiment in $t=10 \mathrm{~min}$, the panel was turned $45^{\circ}$ around its vertical axis by hand. As it is seen in the figure in $t=15 \mathrm{~min}$ when the sun tracking algorithm was again activated, the panel returned to its best position that is perpendicular to the sun direction. It can be also seen that by using maximum power point tracking algorithm, delivered power became $32 \mathrm{~W}$ from its initial value.

\section{Conclusion}

Three methods to maximize the output power of a solar panel were employed in this research. Fuzzy-based maximum power point tracking was the first technique. It is observed that by use of the technique, $23 \mathrm{~W}$ was approximately obtained during the measurement time, which is about 51 percents of the nominal output power. In the second method, fuzzy-based sun tracking was applied and it is observed that $11 \mathrm{~W}$ was approximately attained during the measurement period, which is about 24.5 percent of the nominal output power. The result is expected because sun tracking was only employed without maximum power point tracking and so a small amount of the nominal power was obtained from the solar panel. Finally, the combination of fuzzybased maximum power point tracking and fuzzy-based sun tracking was used to maximize the output power. It can be seen that by stimulus use of those techniques, the output power can reached the amount of $35 \mathrm{~W}$, which is about 78 percents of the nominal output power. The panel was not in its nominal conditions, it is the reason why it could not reach its nominal output power. It was shown that the mixture of the two techniques yields the maximum output power delivery. This achievement can also lead to a reduction of the size, weight, and cost of solar panels in photovoltaic systems.

\section{References}

[1] A. B. G. Bahgat, N. H. Helwa, G. E. Ahmad, and E. T. Shenawy, "Maximum power point tracking controller for photovoltaic systems using neural networks," Elsevier Renewable Energy, vol. 30, pp. 1257-1268, 2005.

[2] E. Demirkutla, U. Erdem Kilic, and O. Ozturk, "Using the neural network model of a solar energy panel in the maximum power point detection," in Proceedings of the International 12th Turkish Symposium on Artificial Intelligence and Neural Networks, vol. 1, 2003.

[3] M. A. S. Masoum and M. Sarvi, "Design, simulation and construction of a new fuzzy-based maximum power point tracker for photovoltaic applications," in Proceedings of the Australasian University Power System Engineering Conference (AUPEC '02), 2002.

[4] C. Y. Won, D. H. Kim, S. C. Kim, W. S. Kim, and H. S. Kim, "New maximum power point tracker of photovoltaic arrays using fuzzy controller," in Proceedings of the 25th Annual IEEE Power Electronics Specialists Conference, pp. 396-403, June 1994.

[5] M. G. Simoes, "Fuzzy optimisation based control of a solar array system," in IEE Proceedings of Electric Power Applications, vol. 146, no. 5, pp. 552-558, 1999.

[6] B. M. Wilamowski and X. Li, "Fuzzy system based maximum power point tracking for PV system," in Proceedings of the 28th Annual Conference of the IEEE Industrial Electronics Society, pp. 3280-3284, November 2002.

[7] N. Patacharaprakiti, S. Permrudeepreechacharn, and Y. Sriuthaisiriwong, "Maximum power point tracking using adaptive fuzzy logic control for grid-connected photovoltaic system," in Renewable Energy, vol. 30, Elsevier, 2005.

[8] A. Nafeh, F. H. Fahmy, and E. M. Abou El-Zahab, "Maximumpower operation of a stand-alone PV system using fuzzy logic 
control," International Journal of Numerical Modelling, vol. 15, no. 4, pp. 385-398, 2002.

[9] T. L. Kottas, Y. S. Boutalis, and A. D. Karlis, "New maximum power point tracker for PV arrays using fuzzy controller in close cooperation with fuzzy cognitive networks," IEEE Transactions on Energy Conversion, vol. 21, no. 3, pp. 793-803, 2006.

[10] C. H. Li, X. J. Zhu, G. Y. Cao, W. Q. Hu, S. Sui, and M. R. $\mathrm{Hu}$, "A maximum power point tracker for photovoltaic energy systems based on fuzzy neural networks," Journal of Zhejiang University. Science A, vol. 10, no. 2, pp. 263-270, 2009.

[11] F. Z. Zerhouni, M. H. Zerhouni, M. Zegrar, M. T. Benmessaoud, A. B. Stambouli, and A. Midoun, "Proposed methods to increase the output efficiency of a photovoltaic (PV) system," Acta Polytechnica Hungarica, vol. 7, no. 2, pp. 55-70, 2010.

[12] P. S. Revankar, W. Z. Gandhare, and A. G. Thosar, "Maximum power point tracking and efficiency enhancements for PV systems," International Journal of Computer Applications, vol. 1, no. 27, 2010.

[13] C.-C. Wang, M.-C. Wu, S.-Y. Ou, K.-J. Lin, and C.-R. Lin, "Analysis and research on maximum power point tracking of photovoltaic array with Fuzzy logic control and three-point weight comparison method," Science China Technological Sciences, vol. 53, no. 8, pp. 2183-2189, 2010.

[14] H. A. Yousef, "Design and implementation of a fuzzy logic computer-controlled sun tracking system," in Proceedings of the IEEE International Symposium on Industrial Electronics (ISIE '99), pp. 1030-1034, July 1999.

[15] F. Huang, D. Tien, and O. R. James, "A microcontroller based automatic sun tracker combined with a new solar energy conversion unit," in Proceedings of the International Conference on Power Electronic Drives and Energy Systems for Industrial Growth, vol. 1, pp. 488-492, 1998.

[16] P. Y. Vorobiev, J. G. Hemhdez, and Y. V. Vorobiev, "Optimization of the solar energy collection in tracking and non-tracking photovoltaic solar system," in Proceedings of the 1st International Conference on Electrical and Electronics Engineering (ICEEE '04), pp. 310-314, September 2004.

[17] A. Garrigos and J. M. Blanes, "Power MOSFET is core of regulated-dc electronic load," University Miguel Hernandez, Electronic Technology Division, Elche, Spain, 2005, http://www.edn.com. 


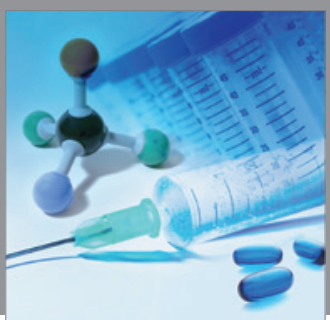

International Journal of

Medicinal Chemistry

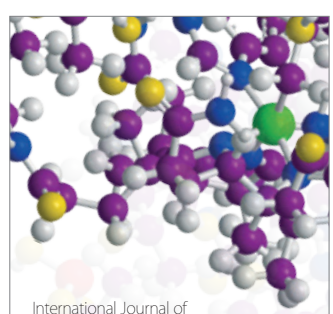

Carbohydrate Chemistry

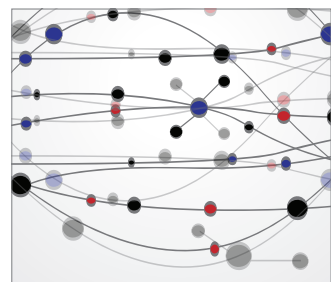

The Scientific World Journal
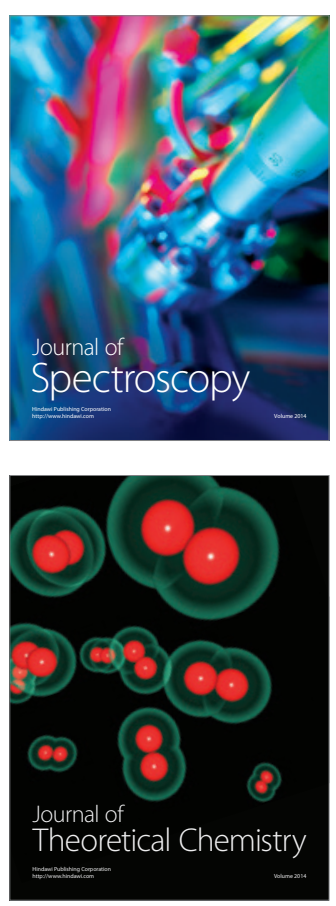
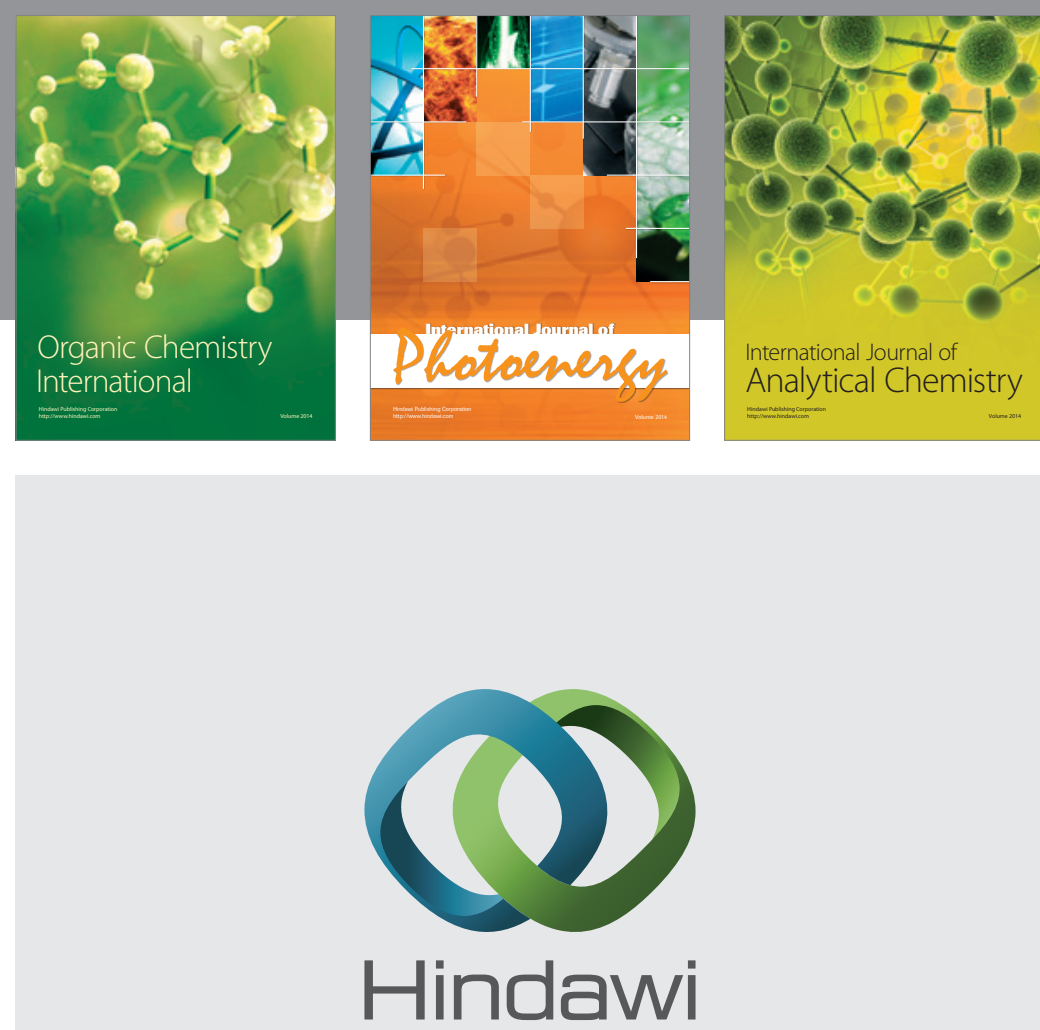

Submit your manuscripts at

http://www.hindawi.com
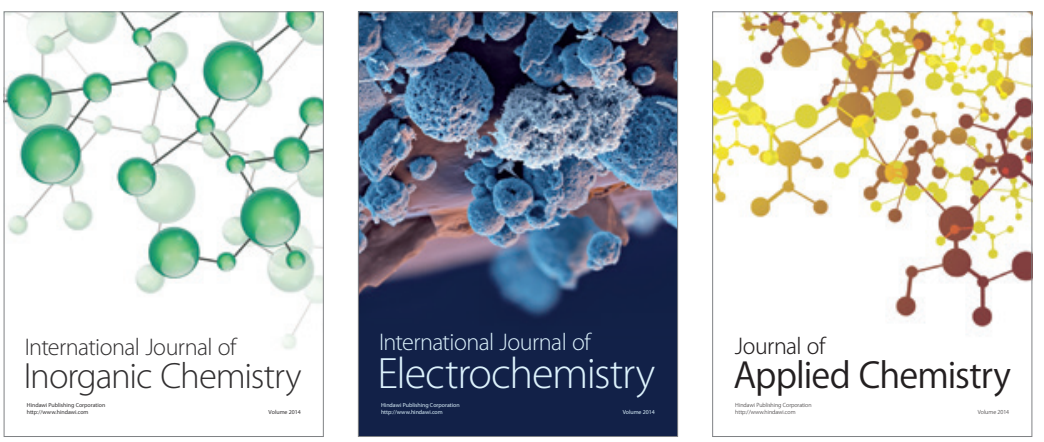

Journal of

Applied Chemistry
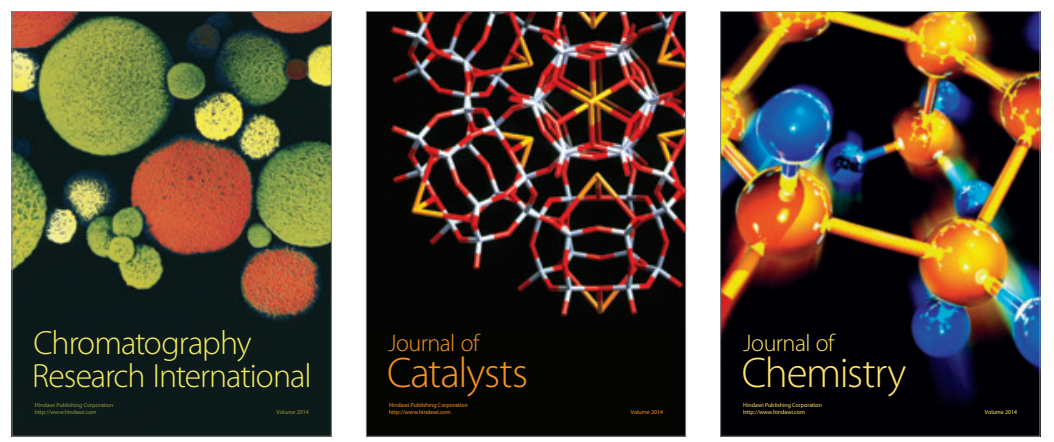
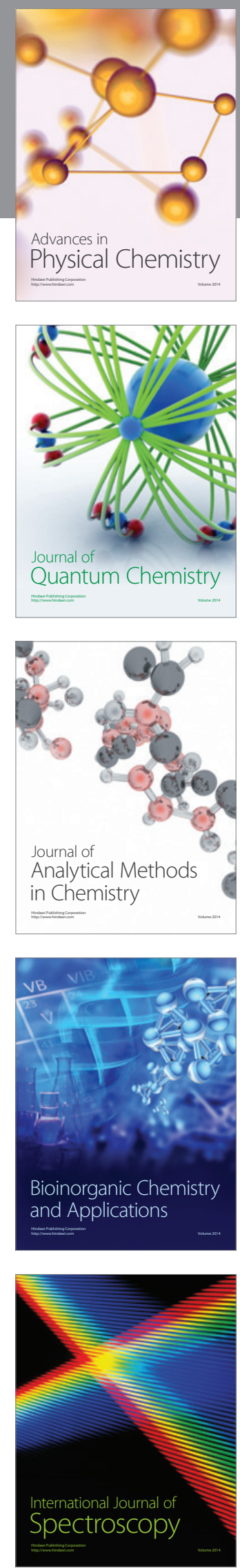